\title{
DINASTIAS POLÍTICAS NO PARLAMENTO BRASILEIRO E O SEU PERFIL IDEOLÓGICO: UMA ANÁLISE DA 55ª LEGISLATURA
}

\author{
DINASTÍAS POLÍTICAS EN EL PARLAMENTO BRASILEÑO Y SU PERFIL \\ IDEOLÓGICO: UNA ANÁLISIS DE LA 55 LEGISLATURA
}

POLITICAL DYNASTIES IN THE BRAZILIAN PARLIAMENT AND ITS
IDEOLOGICAL PROFILE: AN ANALYSIS OF THE 55TH LEGISLATURE

João Roberto dos Reis de SOUZA ${ }^{1}$

RESUMO: O Brasil é uma República de dinastias políticas, visto que se constata a presença dessas famílias em todas as esferas do poder público dos períodos da Colônia, Império, República e na contemporaneidade. A pesquisa procurou investigar a relação direta entre a ascensão do conservadorismo brasileiro e o aumento das dinastias políticas na Câmara dos Deputados. Para isto, foi necessário traçar a trajetória biográfica de todos os 513 deputados e compreender a lógica específica da ação dos deputados pertencentes a dinastias políticas. $\mathrm{O}$ propósito foi verificar em qual espectro político se encontram estes referidos parlamentares.

PALAVRAS-ChAVE: Famílias políticas. Parlamento brasileiro. Ideologias políticas. Sociologia política.

RESUMEN: Brasil es una República de dinastías políticas, ya que estas familias están presentes en todas las esferas del poder público en los periodos de Colonia. Imperio, República y en la época contemporánea. La investigación buscó investigar la relación directa entre el auge del conservadurismo brasileño y el surgimiento de dinastías políticas en la Cámara de Diputados. Para ello, fue necesario trazar la trayectoria biográfica de los 513 diputados y comprender la lógica específica de la acción de los diputados pertenecientes a dinastías políticas. El propósito era verificar en qué espectro político se encuentran estos parlamentarios.

PALABRAS CLAVE: Familias políticas. Parlamento brasileño. Ideologías políticas. Sociología política.

ABSTRACT: Brazil is a Republic of political dynasties, as these families are present in all spheres of public power in the periods of Colony, Empire, Republic and in contemporary times. The research sought to investigate the direct relationship between the rise of Brazilian conservatism and the increase of political dynasties in the Chamber of Deputies. For this, it was necessary to trace the biographical trajectory of all 513 congressman and congresswoman and understand the specific logic of the action of those belonging to political dynasties. The purpose was to verify which political spectrum these parliamentarians are in.

${ }^{1}$ Universidade de Brasília (UNB), Brasília - DF - Brasil. Graduando em Ciências Sociais com habilitação em Sociologia. ORCID: https://orcid.org/0000-0001-5444-7877. E-mail: joaoroberto.pol@gmail.com 
KEYWORDS: Political families. Brazilian Parliament. Political ideologies. Political sociology.

\section{Introdução}

A presença das famílias no âmbito público é um fenômeno constante na história do Brasil. Pimentel (2014) afirma que famílias, enquanto instituição, foram pouco estudadas pelos clássicos teóricos das ciências humanas (Durkheim e Weber), pois acreditavam que este fenômeno se tratava de uma característica pré-moderna. Portanto, com o advento da modernidade e das instituições regidas por normas e burocracia, esta cultura familista desapareceria. No entanto, constata-se empiricamente que estavam equivocados.

Essa estratégia de hereditariedade política é usada em vários países e em diversos regimes políticos. Em Cuba, num regime de feição ditatorial, com os irmãos Fidel e Raúl Castro, nos Estados Unidos, em um regime democrático, George W. Bush sucedeu o pai em 2000, na Argentina, também com o regime democrático, Cristina Kirchner sucedeu o seu marido Néstor em 2007 e, mais recentemente no Uruguai com o Lacalle Pou (PN) filho de Luis Alberto Lacalle que teve mandato como presidente (1990 - 1995).

No Brasil não seria diferente, como tem se constatado (MESSENBERG, 2011), as dinastias políticas são um elemento constitutivo do campo político do Congresso Nacional brasileiro. O pertencimento a uma família com tradição na política mostra-se como um facilitador no recrutamento político e eficiência no pleito de um cargo eleitoral, ou seja, estes indivíduos entram com muitas vantagens e recursos em relação aos outros candidatos que não possuem famílias com tradição no âmbito político.

Para além disso, destaca-se que foi amplamente colocado pela mídia o caráter conservador do Congresso Nacional eleito em 2014, ou seja, a 55ª Legislatura desde o período da redemocratização, pós $1964^{2}$. Na tentativa de explicar este fenômeno, alguns pesquisadores atribuem como consequência a insatisfação com os governos petistas, a crise econômica, as manifestações de 2013, a descrença nas instituições brasileiras, a corrupção e o sentimento de não representatividade política pela sociedade.

Somado a este caráter conservador, considera-se também o aumento das dinastias políticas na $55^{\mathrm{a}}$ legislatura da Câmara dos Deputados. Isto quer dizer que 46,5\% dos parlamentares eleitos e empossados na $55^{\mathrm{a}}$ Legislatura da Câmara dos Deputados fazem parte

2 Disponível em http://politica.estadao.com.br/noticias/geral,diap-congresso-eleito-e-omais-conservador-desde1964,1572550. Acesso em: 10 set. 2020. 
de famílias políticas com pelo menos um(a) antecessor(a) consanguíneo e/ou marido, ou esposa, que ocuparam cargos eletivos nos âmbitos municipal, estadual e/ou federal brasileiros.

Portanto, pergunta-se, qual a relação entre o conservadorismo brasileiro e as famílias políticas? Qual a relação entre família e poder? Em qual espectro político encontram-se estes deputados pertencentes a famílias com tradição na política?

A hipótese levantada neste trabalho é de os deputados federais pertencentes às dinastias políticas se encontram em todo o espectro político ideológico - visto que esta hereditariedade política se encontra em diversos tipos de regime político conforme já mencionado anteriormente. Contudo, enfatiza-se que estes centralizam-se mais à direita. A vista disso, portanto, considera-se que há uma relação direta entre o aumento do conservadorismo brasileiro com o aumento das dinastias políticas no parlamento brasileiro, no entanto não é o único fator ocasionador desse fenômeno.

Conforme já colocado, a presença de famílias na esfera política representativa e administrativa se mostra bastante pertinente em toda história do Brasil desde o período Colonial (OLIVEIRA VIANNA, 1949; HOLANDA, 1976; FAORO, 1975), boa parte dos deputados federais são herdeiros de familiares cujo poder político, em alguns casos, reporta-se ao Brasil Império e que conseguem se metamorfosear ao decorrer das transformações culturais e sociais que a sociedade travessa, permanecendo, portanto, nestas esferas (ADILSON FILHO, 2017).

Esta pesquisa tem o entendimento de que o capital familiar não se trata de uma marca de subdesenvolvimento institucional que ocasiona prejuízos à democracia brasileira. Alguns teóricos defendem a ideia de que a prevalência do capital familiar nas instituições brasileiras é um indício de "atraso" político, tendendo, portanto, a se reduzir com o amadurecimento da democracia no País. (MIGUEL; MARQUES; MACHADO; 2015). As dinastias políticas oligarquizam o sistema legislativo fazendo com que se diminuam as ideias plurais na tomada de decisão dentro do parlamento brasileiro gera-se, portanto, uma representação política da sociedade brasileira distorcida.

De acordo com pesquisa anterior de âmbito nacional, (MESSENBERG, 2011), 32,6\% (167) dos parlamentares eleitos e empossados na 53 ${ }^{\text {a }}$ Legislatura da Câmara dos Deputados fazem parte de famílias políticas com pelo menos um(a) antecessor(a) consanguíneo e/ou marido, ou esposa, que ocuparam cargos eletivos nos âmbitos municipal, estadual e/ou federal brasileiros. Cabe, portanto, mais indagações: por que existe a perpetuação das dinastias políticas no parlamento brasileiro? Qual a relação entre dinastias políticas e poder no Brasil? Por que o recrutamento político brasileiro é permeado pela lógica familista? Por que houve a 
guinada do conservadorismo na Câmara dos Deputados e o aumento considerável das dinastias políticas na mesma legislatura?

\section{Metodologia}

Para Goulart (2016), ainda não há uma metodologia estritamente definida — os pesquisadores que escreveram e escrevem sobre este objeto pertencem a diversas áreas de conhecimento - e este é o motivo principal pelo qual é necessário haver mútua interação e interdisciplinaridade entre a Ciência Política, Sociologia e História para melhor entender a transferência de poder entre os membros das dinastias políticas. Este trabalho se debruça nos métodos quantitativos.

Dessa forma, pretende-se investigar o aumento do conservadorismo na Câmara dos Deputados da $55^{\text {a }}$ legislatura. Para tal, focou-se na revisão bibliográfica sobre dinastias políticas, usou-se fundamentalmente Canêdo (1994; 1995; 1997; 2011; 2015).

Posteriormente, foi elaborado um banco de dados, com variáveis de acordo com os critérios definidos por Messenberg (2011), de deputados federais se enquadrando na condição de titular e empossados, regionalidade em que o parlamentar foi eleito, partido na eleição e atual, cargos eletivos, profissões, pertencimento as dinastias políticas, grau de parentesco e etc. Estas variáveis são capazes de mostrar e entender a composição sociodemográfica, trajetória política e ascendência familiar dos membros de ambas as Legislaturas. Conforme já levantado em pesquisas anteriores (MESSENBERG, 2011), 32,6\% dos parlamentares eleitos e empossados na 53ª Legislatura da Câmara dos Deputados fazem parte de famílias políticas com pelo menos um(a) antecessor(a) consanguíneo e/ou marido, ou esposa, que ocuparam cargos eletivos nos âmbitos municipal, estadual e/ou federal brasileiros.

Portanto, na coleta dos dados, foi levado em consideração principalmente as informações de partidos, bancadas, frentes parlamentares e perfil ideológico. Todas essas informações são capazes de apontar distinções entre aqueles políticos pertencentes às dinastias e os não pertencentes, bem como os posicionamentos dentro do espectro político brasileiro.

Ademais, embasou-se nos Estudos de Ideologia brasileira e Sistema partidário do Brasil, que visam situar os partidos políticos dentro do espectro político a ser construído, levando em consideração a pesquisa de Zucco e Timothy (2011) que mediu a percepção ideológica dos deputados federais e senadores sobre partidos políticos, Bobbio (1995) que 
teceu as definições bases da díade ideológica clássica, e Scheeffer (2018) que sistematizou brevemente as temáticas em pauta no plenário em relação a díade clássica.

Desse modo, a partir da sistematização dos dados coletados, da consolidação e da revisão bibliográfica, o trabalho analisou o aumento ou não de deputados pertencentes às dinastias na Câmara dos Deputados com o recorte específico da $55^{\text {a }}$ legislatura, bem como em qual espectro político os deputados pertencentes às dinastias se encontram e, por fim, se existe uma relação direta entre essas dinastias e o conservadorismo.

\section{A díade ideológica no Brasil}

Parte-se da conceituação das ideologias políticas pela Revolução Francesa. A Assembleia dos Estados Gerais foi instituída com o objetivo de decidir os rumos da França após as grandes revoltas de 1789. No salão em que a Assembleia se reuniu, dois grupos principais debatiam. Do lado esquerdo estavam aqueles alinhados a baixa burguesia e os trabalhadores representados pelos Jacobinos. Do lado direito estavam aqueles que queriam a conciliação com a nobreza e a alta burguesia que, por sua vez, eram representados pelos girondinos. Por fim, no centro estavam aqueles que mudavam frequentemente de posicionamento de acordo com os interesses. Contudo, os partidos políticos mudam suas ideológicas, conforme apontado posteriormente.

Com o fim de estabelecer uma comparação entre a direita conservadora e as dinastias políticas brasileiras é necessário, primeiramente, fazer alguns apontamentos acerca das ideologias políticas do sistema partidário brasileiro e o conservadorismo.

No contexto brasileiro, a esquerda e a direita, no sistema partidário, costumam se reconfigurar constantemente, conforme Zucco e Timothy (2011), os partidos políticos transitam no espectro de esquerda e direita dos anos 1990 até a atualidade. De acordo com a pesquisa dos autores, em 2012, o partido visto entre os parlamentares como mais à esquerda é o PSOL e o mais à direita é o DEM. 
Figura 1 - Gráfico da distribuição de partidos por ideologia política de 1998 a 2014

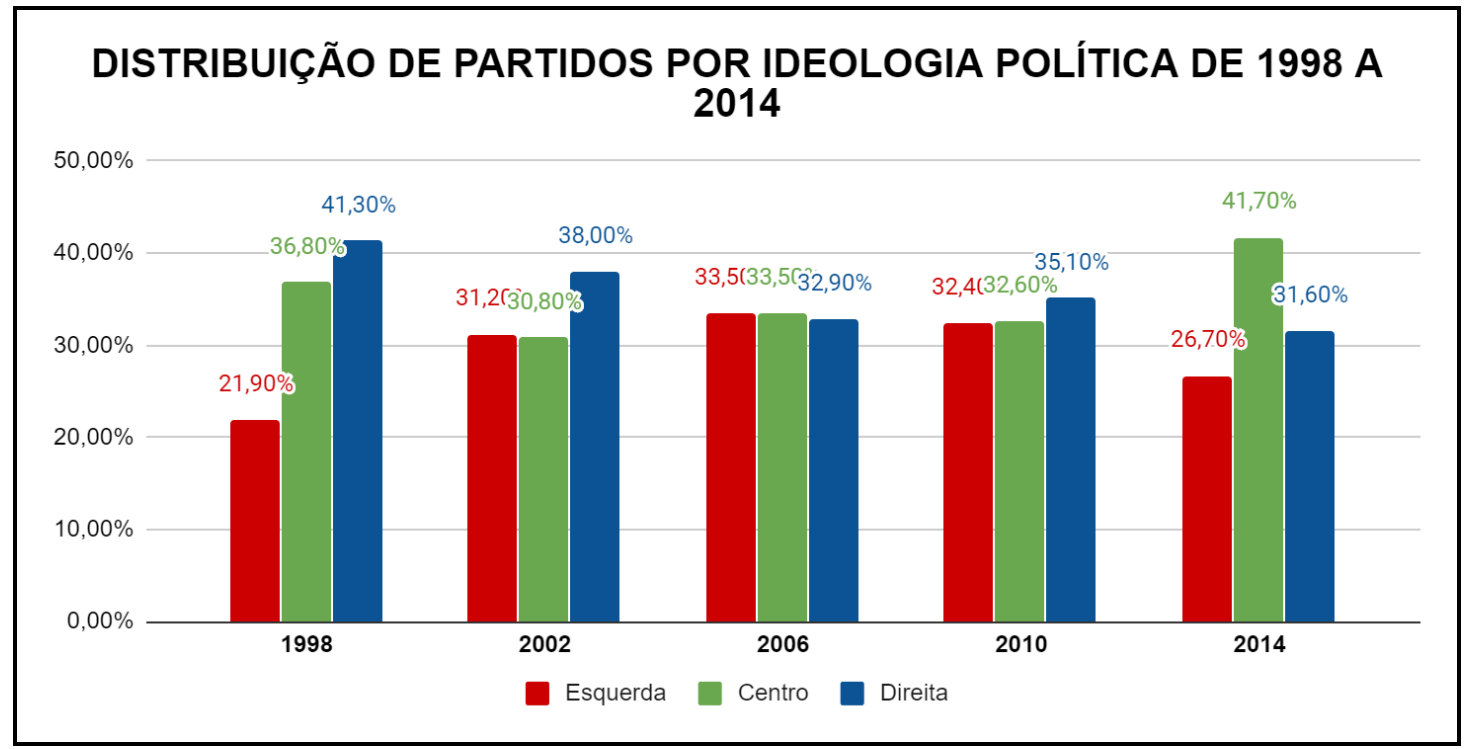

Fonte: Elaboração própria

O gráfico acima mostra as mudanças ideológicas partidárias no Brasil de 1998 a 2014 tomando como referência a Câmara dos Deputados, nota-se o crescimento significativo dos partidos de centro, bem como o decréscimo das ideologias polarizadoras do espectro político (esquerda e direita). Contudo, cabe destacar que houve criação de alguns partidos que se localizam no centro e centro-direita no espectro ideológico, por exemplo, o Partido Podemos (PODE) - antigo PTN -, Solidariedade (SD), PATRIOTA e Partido Republicano da Ordem Social (PROS). O surgimento desses novos partidos aumentou a fragmentação partidária no Parlamento brasileiro.

Tabela 1 - Quadro de divergências em relação a temas ligados às ideologias clássicas

\begin{tabular}{l|l}
\hline \multicolumn{1}{c|}{ Esquerda } & \multicolumn{1}{c}{ Direita } \\
\hline $\begin{array}{l}\text { A intervenção econômica deve dar-se sempre que se } \\
\text { julgar necessário (KEYNES, 1985). }\end{array}$ & $\begin{array}{l}\text { O Estado deve abster-se de questões econômicas, } \\
\text { já que o mercado se autorregula, como se } \\
\text { houvesse uma "mão invisível" orientando esse } \\
\text { processo (SMITH, 1982). }\end{array}$ \\
\hline $\begin{array}{l}\text { A pobreza se dá, sobretudo, por desigualdade de } \\
\text { oportunidades. Enquanto problema social, pode ser } \\
\text { enfrentada via programas sociais ou superação da ordem, } \\
\text { no caso de uma esquerda mais radical (SOUZA, 2009). } \\
\text { A pobreza, quando atacada, deve dar-se de forma } \\
\text { pocalizada e levar à acomodação e ao declínio da "ética } \\
\text { do trabalho" (OLIVEIRA, 2003). }\end{array}$ \\
$\begin{array}{l}\text { A criminalidade pode ser explicada, essencialmente, pela } \\
\text { inserção em um contexto social que oferece } \\
\text { desigualdade de oportunidades (SOUZA, 2009). }\end{array}$ & $\begin{array}{l}\text { A criminalidade, em grande parte, é } \\
\text { responsabilidade dos indivíduos (SOUZA, 2009). }\end{array}$ \\
\hline $\begin{array}{l}\text { A carga tributária deve ser extensiva para financiar o } \\
\text { Os tributos são maléficos, pois sobrecarregam as }\end{array}$
\end{tabular}


Estado e oferecer serviços de qualidade para os que precisarem (COUTO, 2006). empresas e desfavorecem o crescimento econômico (MORAES, 2002; OLIVEIRA, 2003).

O mercado de trabalho deve ser desregulado, visto que o mercado autorregula as relações de trabalho (OLIVEIRA, 2003).

Buscando diminuir o tamanho do Estado, uma boa estratégia é passar para a iniciativa privada serviços que são estatais - privatização (MORAES, 2002; OLIVEIRA, 2003).

*A alocação dos partidos no espectro ideológico a partir da atuação parlamentar Fonte: Scheeffer (2018)

Figura 2 - Comparação escala Esquerda-Direita especialistas versus comportamento efetivo

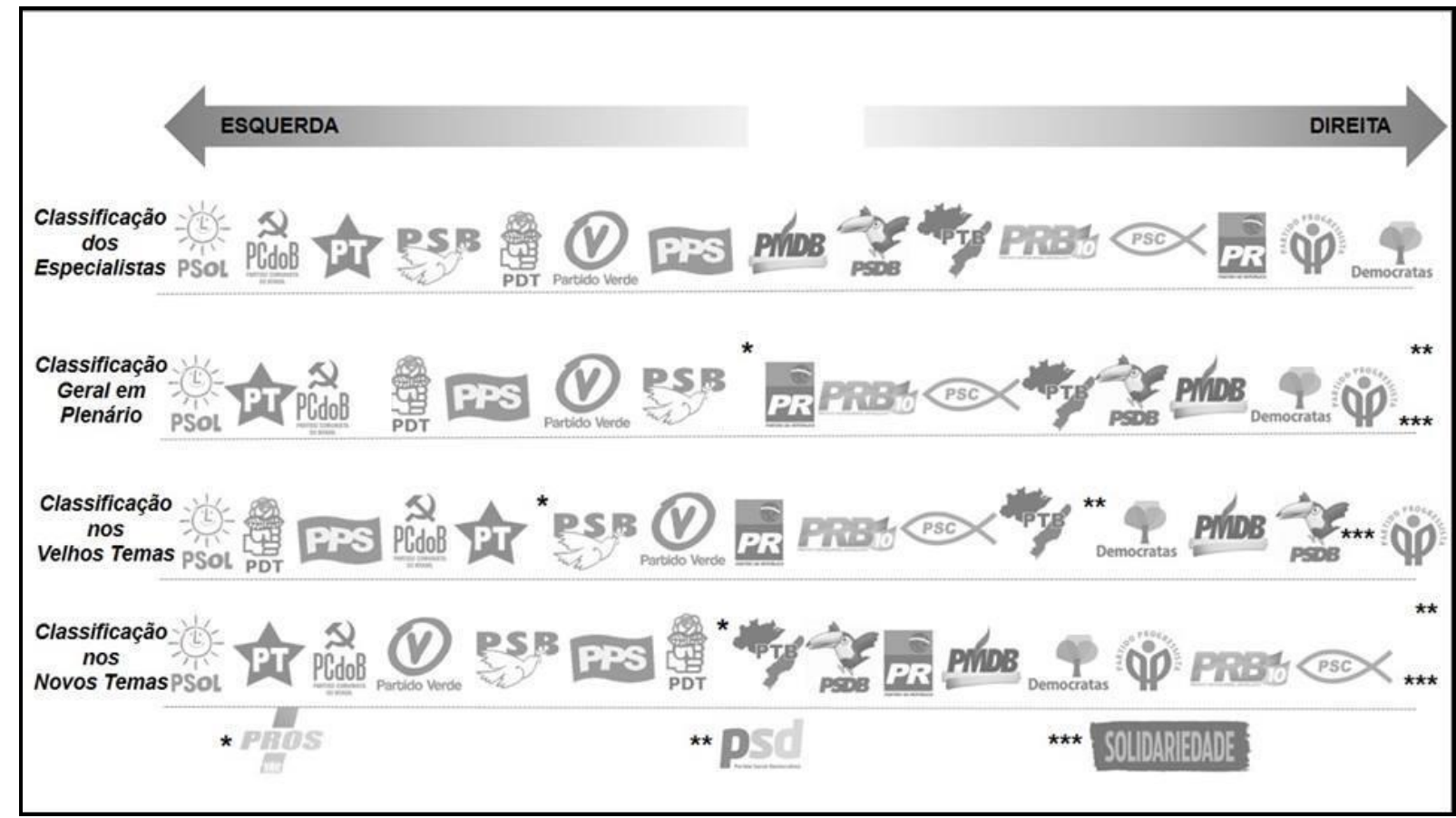

*Classificação dos especialistas

Fonte: Scheeffer (2018)

Conforme apontado, as posições ideológicas partidárias são complexas e, às vezes, flutuantes. Portanto, para além dessas definições ideológicas dos partidos brasileiros é fundamental ressaltar que essas posições partidárias influenciam os indivíduos. Existem vários entendimentos e transformações que esses conceitos sofreram ao longo dos anos, mas, genericamente, compreende-se a direita como uma visão conservadora, de família, religiosa, tradicional, coloca-se a questão econômica como central e considera a desigualdade social como uma consequência da economia, logo comum. Por outro lado, a esquerda foca na questão social embasando-se nos moldes do socialismo (MADEIRA; TAROUCO, 2011). Por conseguinte, ambas vertentes se encontram em posições ideológicas completamente opostas. 
Embora o conservadorismo esteja presente na direita, nem toda direita é composta por conservadores.

A onda conservadora avançou paulatinamente no segundo mandato da ex-presidente Dilma Rousseff, devido a isso surgiu a Proposta Legislativa da Escola sem Partido e, conforme pontuado por Macedo (2017), conservadora buscando mobilizar princípios religiosos, a defesa da família em moldes tradicionais e a oposição a partidos políticos de esquerda e de origem popular.

\section{Bourdieu e as chaves interpretativas}

O ingresso no campo político implica necessariamente na adesão e o compartilhamento do que Bourdieu (2007) chamou de habitus, algo que consiste na orientação dos agentes, bem como de princípios de visão e divisão comuns que organizam as representações coletivas. Isso significa que o ingresso na política predispõe na incorporação do habitus político. Ademais, outros conceitos que auxiliam na explicação do campo político são os de capitais desmembrados abaixo:

O Capital econômico se refere a quantidade de recursos financeiros que o indivíduo dispõe como renda, salários e imóveis. Relevante para a compreensão das desigualdades que permeiam as sociedades;

O Capital cultural, por sua vez, se trata de saberes e conhecimentos reconhecidos por diplomas e títulos, recursos de instruções adquiridos nas instituições escolares. Logo, este capital está intrinsecamente ligado ao investimento escolar, consequentemente, o capital cultural é tido como símbolo de distinção social; e

O Capital social consiste nas relações sociais, rede de contatos que podem ser convertidas em recursos de dominação, conferindo, portanto, vantagem sobre os demais indivíduos.

Por conseguinte, é possível afirmar que o acúmulo e a composição do dos capitais está diretamente ligada a eleição no campo político, bem como sua posição no estrato do Congresso Nacional.

\section{Dinastias políticas e suas características}

Conforme já colocado, essa temática de tradição familiar em instituições políticas e administrativas no Brasil não foi amplamente explorada pelos pesquisadores, portanto ainda 
necessita de estudos mais aprofundados. Essa agenda foi retomada pelas Ciências Sociais nos anos 1990 principalmente com Canêdo (1994; 1995; 1997; 1998; 2005; 2011). Raymundo Faoro (1975) desenvolve a ideia de que a peculiaridade administrativa brasileira se deu pela burocracia estamental patrimonialista que caracterizava a dinâmica social, política e econômica brasileira. $\mathrm{O}$ autor define como patrimonialismo "[...] aquela forma de dominação tradicional em que o soberano organiza o poder político de forma análoga ao seu poder doméstico" (FAORO, 1975).

Além disso, Faoro aponta como especificidade brasileira que a dominação patrimonial se manteve inalterada por um período da história brasileira.

DE DOM JOÃO I A GETÚLIO VARGAS, numa viagem de seis séculos, uma estrutura político-social resistiu a todas as transformações fundamentais, aos desafios mais profundos, à travessia do oceano largo (FAORO, 2008, p. 822).

Argumenta que a importância desse estamento burocrático remontava a própria formação do estado-nação português, em que a casa real desde pronto logrou ocupar lugar de destaque na sociedade e a suprimir qualquer poder paralelo que lhe representasse ameaça. Dessa forma, os colonos viram-se sufocados pelo Estado absolutista e por sua burocracia centralizadora e patrimonialista.

Por outro lado, para a perspectiva contemporânea, de acordo com Canêdo (1994; $1995 ; 1997 ; 2002 ; 2011 ; 2015)$, o ingresso na carreira política de membros de certos grupos familiares resulta tanto do processo da socialização política e sua reprodução, o qual inclui rituais que perpassam por práticas confirmadoras de vocações e requer o domínio de regras. Em suas palavras:

[...] é uma educação voltada para a duração e baseada em experiências que devem ser transmitidas por meio de exemplos concretos, visando juntar as pessoas a partir de uma mesma visão do mundo, oferecendo-lhes uma identidade. Dessa maneira, procura misturar, na mente dos indivíduos, a memória específica familiar com as lembranças ligadas à sociedade em geral. Assim, faz parte das atividades de qualquer criança dessas famílias participar dos acontecimentos sociais locais, cumprimentar convidados, parentes e amigos, aprender a sorrir, deixar brinquedos e frequentar festas de casamento na roça, escutar distraidamente conversações de políticos, acompanhar o trabalho entre os eleitores e a "elevação da temperatura" na vida familiar às vésperas das eleições, e perceber os pequenos cuidados necessários para dominar os detalhes do jogo básico do homem político" (CANÊDO, 1997. p. 17).

Dessa forma, os descendentes das dinastias políticas são socializados politicamente diariamente, recebem políticos em jantares, participam dos comícios e eventos promovidos 
pelos pais, em resumo, acompanham os pais nas atividades políticas. Muitos deputados relatam terem sido preparados a vida toda para ingressarem na carreira política.

Parte significativa das dinastias políticas iniciam sua carreira política em cargos eletivos nos municípios e, no momento de ingresso na carreira política, estes deputados pertencentes às dinastias políticas, herdam toda rede de contatos já construída pelo antecessor político, possuem capital econômico, prestígio social, bem como se beneficiam do eleitorado. Estes mesmos deputados dispõem de corpus de saberes específicos, domínio prático do jogo político. O que os colocam em vantagem em relação aos demais candidatos seja em campanhas ou dentro da Câmara dos Deputados.

O objetivo desta pesquisa foi verificar em qual espectro político se concentram as dinastias políticas do Parlamento brasileiro referente à 55ª Legislatura. Para tal, construiu-se uma tabela que considerou a bancada partidária, as famílias pertencentes às dinastias políticas e os partidos políticos.

Tabela 2 - Quadro referente ao quantitativo das bancadas partidárias e dinastias políticas por partido da $55^{\mathrm{a}}$ Legislatura.

\begin{tabular}{c|c|c|c}
\hline \multicolumn{3}{|c}{ 55 $^{\text {a }}$ LEGISLATURA } \\
N & PARTIDOS & BANCADA & DINASTIA \\
\hline 1 & PMDB & 59 & 34 \\
\hline 2 & PSD & 41 & 27 \\
\hline 3 & PSDB & 53 & 22 \\
\hline 4 & PT & 66 & 21 \\
\hline 5 & PSB & 31 & 20 \\
\hline 6 & PP & 40 & 19 \\
\hline 7 & PR & 33 & 14 \\
\hline 8 & PTB & 26 & 14 \\
\hline 9 & DEM & 26 & 13 \\
\hline 10 & PDT & 17 & 10 \\
\hline 11 & SD & 18 & 8 \\
\hline 12 & PRB & 22 & 7 \\
\hline 13 & PROS & 10 & 5 \\
\hline 14 & PSC & 14 & 5 \\
\hline 15 & PPS & 9 & 4 \\
\hline 16 & PTN & 4 & 2 \\
\hline
\end{tabular}


Fonte: Elaboração própria

\begin{tabular}{c|c|c|c}
\hline 17 & PV & 9 & 2 \\
\hline 18 & PCdoB & 10 & 2 \\
\hline 19 & PSOL & 6 & 0 \\
\hline 20 & PEN & 2 & 1 \\
\hline 21 & PHS & 4 & 1 \\
\hline 22 & PL & 1 & 1 \\
\hline 23 & PMN & 2 & 1 \\
\hline 24 & PODE & 2 & 1 \\
\hline 25 & PSL & 2 & 1 \\
\hline 26 & PTC & 2 & 1 \\
\hline 27 & PTdoB & 1 & 1 \\
\hline 28 & PATRI & 1 & 0 \\
\hline 29 & PRP & 1 & 0 \\
\hline 30 & PRTB & 1 & 0 \\
\hline \multicolumn{2}{|c|}{ TOTAL } & $\mathbf{5 1 3}$ & $\mathbf{2 3 7}$
\end{tabular}

Figura 3 - Gráfico da distribuição de partidos por ideologia política dos deputados pertencentes às dinastias políticas da $55^{\mathrm{a}}$ Legislatura

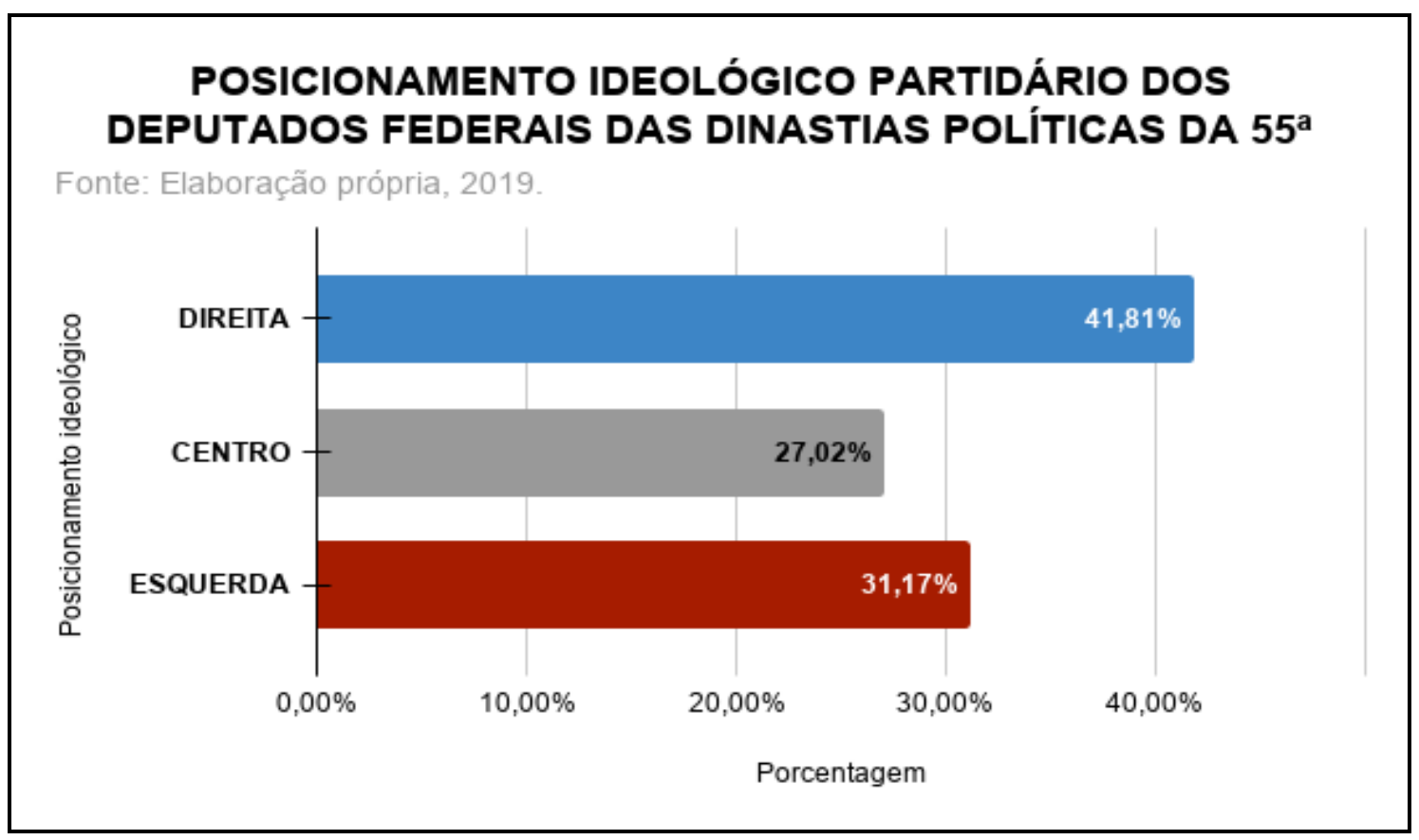

Fonte: elaboração própria

De acordo com o gráfico acima, elaborado de acordo com os critérios estabelecidos por Scheeffer (2018), as dinastias políticas estão presentes em todo o espectro ideológico, 
contudo concentram-se mais à direita $(41,81 \%)$ em relação à esquerda $(31,17 \%)$ e ao centro $(27,02 \%)$. É razoável atribuir também o aumento do conservadorismo no Parlamento brasileiro à presença de dinastias políticas.

\section{Considerações finais}

O principal objetivo desta pesquisa foi investigar a relação direta entre a retomada do conservadorismo brasileiro e o aumento das dinastias políticas no parlamento brasileiro.

Cabe pontuar primeiramente que deputados federais pertencentes às dinastias políticas passam por uma espécie de investimento, desde o berço são socializados para o exercício da atividade política. Dessa forma, "Nascer na política" significa necessariamente herdar, através da transmissão familiar, recursos e capitais para adesão e atuação no campo político. $\mathrm{O}$ resultado dessa equação é a perpetuação das dinastias políticas nas instituições públicas.

Os dados do estudo explanaram a relação direta entre as dinastias políticas no parlamento brasileiro com a $55^{\mathrm{a}}$ legislaturas. Demonstrou-se, portanto, que o processo de recrutamento político para a Câmara dos Deputados é permeado por lógicas de seleção e reprodução hereditárias e/ou de parentesco, dado que 237 (46,5\%) deputados federais contém ascendência familiar na política institucional.

Observou-se, em termos ideológicos partidários, na $53^{\mathrm{a}}$ legislatura que os deputados pertencentes às dinastias políticas se distribuem nos seguintes partidos: PMDB, PSDB, PFL, PP, PSB, PT, PL, PTB, PDT, PCdoB (MESSENBERG, 2011). Em contrapartida, para a 55 legislatura, têm-se: MDB, PSD, PSDB, PT, PSB, PP, PR, PTB, DEM, PDT.

Por fim, é possível dizer que o capital familiar é uma das características marcantes da política brasileira devido a concentração de deputados pertencentes às dinastias políticas em partidos de direita e centro-direita, bem como o aumento do conservadorismo foi influenciado devido a permanência da lógica hereditária na Câmara dos Deputados, porém, considera-se que não foi o único fator responsável pela guinada à direita no Parlamento. Sobretudo, sugerese estudos mais amplos sobre as dinastias políticas principalmente a nível municipal e estadual.

\section{REFERÊNCIAS}

BOBBIO, N. Direita e esquerda: razões e significados de uma distinção política. São Paulo: Unesp, 1995. 
BOURDIEU, P. O poder simbólico. 11. ed. Rio de Janeiro: Bertrand Brasil, 2007.

CANEDO, L. As metáforas do parentesco e a duração em política. Cadernos Cedes, n. 42, 1997.

FAORO, R. Os donos do poder. São Paulo: Globo, 2008

FILHO, J. A. Flexibilizando para não quebrar: famílias políticas tradicionais e suas estratégias de permanências no poder. Revista Campo da História, v. 2, p. 01-15, 2017.

GOULART, M. H. H. S. Entre famílias e secreta-rias: análise do arranjo político administrativo da Paraná (1889-1930). In: OLIVEIRA, R. C. (Org.). Estado, Classe Dominante e Parentesco no Paraná. Blumenau: Nova Letra, 2015. p. 247-300.

GRILL, I. G. Parentesco, redes e partidos: as bases das heranças políticas no Rio Grande do Sul. 2003. Tese (Doutorado em Ciência Política) - Universidade Federal do Rio Grande do Sul, Porto Alegre, 2003.

HOLANDA, S. B. Raízes do Brasil. São Paulo: Companhia das Letras, 1995.

MESSENBERG, D. O alto e o baixo clero do parlamento brasileiro. In: ENCONTRO ANUAL DA ANPOCS, 33., 2009, Caxambu. Anais [...]. Minas Gerais, 2009.

MIGUEL, L. F. Capital político e carreira eleitoral: algumas variáveis na eleição para o congresso brasileiro. Rev. Sociol. Polit., Curitiba, n. 20, p. 115-134, jun. 2003.

MIGUEL, L. F.; MARQUES, D.; MACHADO, C. Capital familiar e carreira política no brasil: gênero, partido e região nas trajetórias para a câmara dos deputados. Dados, v. 58, p. 721-747, 2015.

OLIVEIRA VIANNA, J. J. Instituições políticas brasileiras. Brasília, DF: Coleção Biblioteca Básica Brasileira, Senado Federal, 1999.

PIMENTEL, V. M. A primazia dos clãs: a família na política nordestina. 2014. Tese (Doutorado em Ciência Política) - Universidade Federal de Pernambuco, Recife, 2014.

SCHEEFFER, F. A alocação dos partidos no espectro ideológico a partir da atuação parlamentar. 2018.

TAROUCO, G. S.; MADEIRA, R. M. Partidos, programas e o debate sobre esquerda e direita no Brasil. Revista de Sociologia e Política, v. 21, n. 45, p. 149-165, 2013.

ZUCCO, C.; TIMOTHY, J. (Orgs.). O Congresso por ele mesmo: autopercepções da classe política brasileira. Belo Horizonte: UFMG, 2011. 


\section{Como referenciar este artigo}

SOUZA, J. R. R. Dinastias políticas no parlamento brasileiro e o seu perfil ideológico: uma análise da 55a legislatura. Rev. Sem Aspas, Araraquara, v. 9, n. 2, p. 261-274, jul./dez. 2020. e-ISSN: 2358-4238. DOI: https://doi.org/10.29373/sas.v9i2.14634

Submetido em: 10/01/2021

Aceito em: 23/02/2021

Publicado em: 01/03/2021 